\title{
OUR TRIAL IN PROBLEM-ORIENTED TEACHING FOR PATHOPHYSIOLOGY
}

\author{
Marinov M., G. Bekyarova, R. Zl. Radev, K. Mirchev, M. Hristova \\ Department of Pathophysiology, Medical University - Varna
}

Reviewed by: Assoc. Prof. N. Negrev

\begin{abstract}
The decision for clinical cases during pathophysiology is linked with the introduction of problem-oriented learning in pathophysiology through the next few years. "Clinical cases" from general medicine (arterial hypertension, diabetes mellitus, pancreatic insufficiency, cerebral vascular disease, etc) are examined in the framework of two sessions. On the basis of a short description of the patient the students develop hypotheses for the possible causes which lead to the pathogenic connection between the cause, the afflicted structure and function, symptom, syndrome and illness. The difficulty which the students most often face is connected with the basis of the hypothesis, which they must relate knowledge from the fundamental sciences and general pathophysiology in order to solve concrete clinical cases. Analyses of the results are made of the students' difficulties during solving of clinical cases as well as the necessary path for overcoming it. On the basis of our investigation, we consider that the decision of clinical cases makes learning pathophysiology more engaging for the student, creating conditions for independent preparation and local thinking, which are necessary of the students for solving patient problems.
\end{abstract}

Key words: Problem-based learning, Pathophysiology

\section{INTRODUCTION}

The social meaning of the medical profession is due to it being one of the fastest growing applications of science. It is accelerating and progressive, however the absorption and application of this enormous volume of difficult science information in the study of medicine and medical practice is difficult to absorb (9). Thus, the necessity of effective methods for training students of medicine, results to this, during the 60 years of the last century in the USA resulted to the method of problem based learning (PBL) (1). Through the following years many medical students in the USA are starting to acquire different methods and forms of PBL, changing one or another step in the traditional program, fundamentals of lectures and laboratory exercises, towards problem-based, student-centered program, in which a considerable part from learning is borrowed from tutoring sessions (1). Already a considerable volume of literature, is supporting the statement that in comparison with the generally accepted, lecture based instruction, PBL of the preclinical sciences has the following priorities:

1. improve on the ability of the students for choosing of problems $(10,11)$;

2. improve on understanding and memory of the basic sciences $(6,8)$;

Address for correspondence:

R. Zl. Radev, Dept. of Pathophysiology, MU-Varna

55 Marin Drinov Str.

e-mail: pathophysiology@mu-varna.bg
3. improve on the work in the clinical setting (17).

Last but not least - the students enjoy using PBL are involved and active in the process of training (2), and this is a specially important priority in comparison with the generally accepted program. All of these advantages of PBL served us like an incentive, to quickly acquire this type of instruction in the department of Pathophysiology, applying the trials of our colleagues from the Medical University - Pleven in which the seminar lessons of Pathophysiology are based on a new form of teaching-solving problem cases. The purpose of this management, in essential interactive approach is to, through an increase of motivation of the students for self preparation and building of logical thinking, and for them to acquire the proper thinking skills for applying their knowledge from preclinical problems to concrete patient - in clinical environment.

Pathophysiology is especially the proper discipline for the application of such an approach showing a natural bridge, integrated component, between preclinical and clinical disciplines, arranging the education from the basic sciences biochemistry, biophysics, physiology, etc. by solidifying the chain links of the pathogenesis and its processes. Connecting preclinical and clinical, the pathophysiology is in the position to realize how the horizontal, as well as the vertical integration between the medical sciences (5). This connective and integrative role of pathophysiology can be illustrated through one typical example - the gradual accumulation of biochemical, biophysical, physiological and other changes, settling in during the presence and in the re- 
sult of persistent arterial hypertension, which unify in one general pathological mechanism and appearance.

In the present article we arranged, for the purpose to share our trials - advantages and problems which originated through 3 years of continuous usage in teaching pathophysiology by problem-oriented case, examining arterial hypertension.

\section{METHODS}

The problem case "Arterial Hypertension" is presented with descriptions of the problems of a patient with above normal arterial blood pressure. It is prepared from the collaborations of the department of pathophysiology on the basis of the history of the disease of real patients. The conclusion of the data results is constructed, in such a way like perceiving an image, possibly the most connected to the typical course of the illness. The case examines the seminar studies of pathophysiology in 2 sessions, includes 2 succeeding drills. During the first session the students familiarize with only the worst complains of the patient, which firstly go to the physician, without the arrangement of a detailed patient history. They receive oral mnemonic help from the tutor which reminds them of the possibly injured organ systems in the organism and the pathophysiological processes, which are possible.

Based on the data and mnemonical help, the students build a list of the most possible hypotheses for the probable causes, leading to the complaints of the patient after the formulation of the hypotheses and discussing their relationship with the pathological connection between the complaints, damaged structures, disordered functions, and probable disease - containing the pathogenesis and its link to the injuries. By this way the students are trained to protect the truthfulness of their hypotheses and simultaneously assimilate principles of the logical clinical perspective.

After this the students receive the remaining information for this clinical case - detailed patient history and data of the physical examination of the patient. With their help, analysis of their most important hypotheses is done while others are rejected. Through the time between the first and the second sessions the students are given the possibility to make the use of all additional sources of information including resources for self preparation: textbooks, monographs, scientific journals, lectures, etc. Their task is to estimate which resources are necessary, supplied through laboratory or instrumental examination of the patient. During the second session is discussed the concrete plan for such examinations, after which the received results are examined. A selection is made of the most precise hypotheses which contain the general direction for treatment.

\section{RESULTS AND DISCUSSION}

The results from the work of the students for the 3 year teaching period of the clinical case "Arterial Hypertension" shows, the greatest part from them is active participation in the making and framing of the hypotheses and in the comparatively good orientation in the cause-effect dependencies, and advancers in the organism during the presence of lasting increased arterial blood pressure. Normally every group formulates between 20-25 hypotheses which explains the complex of symptoms - presented to them in the beginning of the first session.

Owing to the oral mnemonic assistance from the tutor, the students are directed towards the functional systems, which have the largest probability of being involved in the pathological processes, leading to the complex of symptoms.

The largest difficulties are encountered during:

1. Consideration of hypotheses, in connection with the systems, which are not directly connected with the complaints, but perhaps the injury instead;

2. The giving of proof of the hypotheses;

3. Differentiation of the primary and symptomatic nature hypertension;

4. Inclusion of all the systems and illnesses, which are possible sources of the complex of symptoms of hypertension;

5. Consideration of the risk factors for the cause of arterial hypertension.

The capability of building a hypothesis is an essential prerequisite for the assimilation of the clinical perspective main attribute of the physician's profession. They may reach to their complications by two varying ways - inductive and hypothetical-deductive (7).

Inductive is used with the entirety of information from the given problem - it is wide spectrum, and difficult to separate the primary points from the secondary ones, while simultaneously trying to prevent overlooking important information; a lack of enough trials and knowledge is highly unlikely. With the conglomeration of experience and learning there presents the possible use of the hypothetical-deductive method, during which the identification from the symptoms and signs and character of the given pathological process quickly direct one towards the corresponding hypothesis, which by this way demands for purposeful search of information, the findings of which confirm, but the lack of it - rejects the elevated hypothesis. The role of the tutor in this process is to understand the creation of habits from the students in building diagnostic algorithms for differentiating the primary information from the secondary, the causes from the consequences of the cause - consequence chain $(3,16)$.

For the clarification of the diagnosis, order with the patient history and the immediate examination from the doctors, which include instrumental and figurative methods, such as in row laboratory tests. If the subjective (symptoms) and the objective (signs) of the illness including laboratory findings unite in the general concept and are available, for example 20 indications which are classified into to criteria - nor$\mathrm{mal} /$ pathological, furthermore it is to receive a possible 230 combinations. With 3 criteria (normal/high/low) - possible combinations are greater than 3 million, but during 5 criteria are nearly possible 1014 possibilities. This complexity of the diagnostic process is involved in the explanation of 
the "why" and until today it cannot be created without a valid mathematical model $(13,14)$, so, that the estimation of these possibilities for the well qualified physician continue to be unique - is independent if inductive or deductive approaches for this are used (15), but its training is an enormous task which obliges one to look for the maximally effective way for teaching, such as - with moderate optimism it can be difficult - is also perceived by us, in the department of pathophysiology, methods for problem - based teaching. In accordance with this, the form of teaching "problem case" is comfortable and maximally verifies the way for checking the steps in mastering the knowledge for the fundamental pathophysiological norms, a study from general pathophysiology, so for the addition of this knowledge in the moment, if it is shown that it is insufficient through their illustrations with concrete examples and disorders, such as in the problem case "Arterial Hypertension". A small part from the students are weaker and require tutoring intervention orienting their work, and to encouraging them to partake in discussions. During inspection of the problem case, the difficulty for the students to a large degree is due to a badly developed method for execution of the preclinical sciences during work with concrete cases of the illness - not mastering logical clinical thinking skills but instead taking in use of study materials for ones own use, because normally teaching is much more weakly interactive and is not so closely tied with the remaining sciences (5). By the same reasoning the students are weakly motivated to investigate preclinical sciences - such as with the traditional way for teaching, similarly it is not effective in their application in the clinic. Last but not least - the traditional way leads to the reservation of more time towards attending lectures and laboratory exercises, leaving students with little time to study.

It appears that problem based learning is yet more effective, when is applied the synchronous assistance of development of the diagnosis and clinical thought, such as figuratively diagnostic and clinical laboratories. By this way it is possible to run a large part of the insufficiencies of the traditional teaching $(6,8)$, like the simultaneously feasible better horizontal and vertical integration for teaching $(4,12,18)$.

\section{CONCLUSION}

In conclusion it is possible to say that in spite of our small trial in the use of problem cases and the partial application of problem oriented teaching in students of pathophysiology, it is reported that there is an increase of their interest in the utilization of time by this type of laboratory exercise in comparison with the traditional. There is a marked increase in their motivation for participating in discussions and using their acquired knowledge of basic medical principles - a sign and good reason for considering and changing the traditional style of teaching and adopting PBL, with the purpose of comprehending the taught and necessary knowledge from serious professional training and to supply them with purposeful activity and individual capability for acquiring it as well as continuing their actualization.

\section{REFERENCES}

1. Anderson W.L., R.H. Glew. Support of a problem-based learning curriculum by basic science faculty. Med Educ Online [serial online], 2002, 7: 10. http://www.med-ed-online.org

2. Antepohl W., S. Herzig. Problem-based learning versus lecture-based learning in a course of basic pharmacology: a controlled, randomized study. Med. Educ, 1999, 33: 106-113.

3. Barrows H.S., G.R. Norman, V.R. Neufield, J.W. Feightner. The clinical reasoning process of randomly selected physicians in general medical practice. Clin Invest Med, 1982, 5: 49-55.

4. Dahle L.O., J. Brynhildsen, M. Behrbohm Fallsberg, I. Rundquist et al. Pros and cons of vertical integration between clinical medicine and basic science within a problem-based undergraduate medical curriculum: examples and experiences from Linkoping, Sweden. Med Teach, 2002, 24: 280-185.

5. Dimova, S., M. Marinov, K. Demireva. Pathophysoilogy and the new strategies for medical education. Bulg. Medicine, 2002, 10, ${ }^{1} \quad 2: 28-30$.

6. Dods R.F. An action research study of the effectiveness of problem-based learning in promoting the acquisition and retention of knowledge. J Educ Gifted, 1997, 20: 423-437.

7. Elstein A.S., M.J. Loupe, J.B. Erdmann. An experimental study of diagnostic thinking. Journal of structured learning; 1971; 2: 45-53

8. Finucane P.M., S.M. Johnson, D.J. Prideaux. Problem-based learning: its rationale and efficacy. Med J Aust, 1998, 168: 445-448.

9. Goswami U. Neuroscience and education: from research to practice? Nat Rev Neurosci, 2006, 7: 406-411.

10. Hmelo C.E. Problem-based learning: Effects on the early acquisition of cognitive skill in medicine. $J$ Learning Sci, 1998, 7: 173-208.

11. Hmelo C.E., G.S.Gotterer, J.D. Bransford. A theory-driven approach to assessing the cognitive effects of PBL. Instructional Science, 1997, 25: 387-408.

12. Lie N. Traditional and non-traditional curricula. Definitions and terminology. Tidsskr Nor Laegeforen, 1995, 115: 1067-1071.

13. Miller M.C., M.C. Westphal, J.R. Reigart. Mathematical models in medical diagnosis. Praeger, New York, 1981.

14. Murphy E.A. Probability in medicine. Johns Hopkins University Press, Baltimore, 1979.

15. Murphy E.A. The logic of medicine. Johns Hopkins University Press, Baltimore, 1976.

16. Research committee of the College of general practicioners 1958. The continuing observation and recording of morbidity. J Coll Gen Pract, 1958, 1: 107-128.

17. Schwartz R.W., J.E.Burgett, A.V.Blue et al. Problem-based learning and performance-based testing: Effective alternatives for undergraduate surgical education and assessment of student performance. Med Teacher, 1997, 19: 19-23.

18. Vidic B., H.M. Weitlauf. Horizontal and vertical integration of academic disciplines in the medical school curriculum. Clin Anat, 2002, 15: 233-235. 